\title{
STRATEGI PENGEMBANGAN KEMITRAAN AGROINDUSTRI NILAM DI KABUPATEN KONAWE SELATAN MENGGUNAKAN METODE ANALISIS SWOT DAN AHP
}

\section{PATCHOULI AGRO-INDUSTRY PARTNERSHIP DEVELOPMENT STRATEGY IN KONAWE SELATAN DISTRICT USING SWOT AND AHP ANALYSIS METHODS}

\author{
Dzulkarnain $^{1) *}$, Imam Santoso ${ }^{2)}$, dan Siti Asmaul Mustaniroh²) \\ ${ }^{1)}$ Programn Magister Teknologi Industri Pertanian-Fakultas Teknologi Pertanian-Universitas Brawijaya \\ Jalan Veteran-Malang 65145, Indonesia \\ *E-mail: kingdzulkarnain93@gmail.com \\ ${ }^{2}$ Program Studi Teknologi Industri Pertanian-Fakultas Teknologi Pertanian-Universitas Brawijaya \\ Jalan Veteran-Malang 65145, Indonesia
}

Makalah: Diterima 3 Januari 2020; Diperbaiki 30 Maret 2020; Disetujui 10 April 2020

\begin{abstract}
Patchouli oil is one of the export commodities of essential oil which has high economic value. This shows the need to develop patchouli oil cultivation and processing at the farm level, especially in South Konawe Regency. The purpose of this study was to obtain an agro-industry strategy in terms of partnerships both in the production and marketing aspects. The stages of this research began from the field study by interviewing patchouli oil agroindustry actors in South Konawe. The analytical method used was a combination of SWOT (Strengths, Weaknesses, Opportunities, Threats) and Analytical Hierarchy Process (AHP) techniques to get strategic priorities. The results of this study found that the patchouli agro-industry partnership system applied today consists of two patterns including the plasma core pattern for the production aspect and the general trade pattern for the marketing aspect. Furthermore, the alternative strategy that has the highest priority was to increase wider market access by establishing partnerships with a score of 0.369 , the second priority was to conduct training in human resource development in collaboration with related agencies with a score of 0.250 . The third priority was to strengthen capital by utilizing business networks and the internet to overcome the price game with a score of 0.206, and the last priority was to expand partnerships (parthnership) of patchouli farmers and entrepreneurs in increasing production.
\end{abstract}

Keywords: patchouli oil, partnership, development strategy, SWOT, AHP

\section{ABSTRAK}

Minyak nilam merupakan salah satu komoditi ekspor jenis minyak atsiri yang memiliki nilai ekonomi tinggi. Hal ini menunjukkan perlunya dilakukan pengembangan budidaya dan pengolahan minyak nilam ditingkat petani khususnya di Kabupaten Konawe Selatan. Tujuan penelitian ini untuk mendapatkan strategi agroindustri dari sisi kemitraan baik dalam aspek produksi maupun aspek pemasaran. Tahapan penelitian ini dimulai dari studi lapangan dengan mewawancarai pelaku agroindustri minyak nilam di Konawe Selatan. Metode analisis yang digunakan adalah kombinasi SWOT (Strenghts, Weaknesses, Opportunities, Threats) dan teknik Analytical Hierarchy Process (AHP) untuk mendapatkan prioritas strategi. Hasil penelitian ini ditemukan bahwa sistem kemitraan agroindustri nilam yang diterapkan saat ini terdiri dari dua pola diantaranya pola inti plasma untuk aspek produksi kemudian pola dagang umum untuk aspek pemasaran. Selanjutnya alternatif strategi yang memiliki prioritas tertinggi adalah meningkatkan akses pasar yang lebih luas dengan menjalin kemitraan dengan skor 0,369, prioritas kedua adalah melakukan pelatihan pengembangn SDM dengan bekerjasama oleh dinas terkait dengan skor 0,250. Prioritas ketiga adalah memperkuat permodalan dengan memanfaatkan jaringan bisnis dan internet untuk mengatasi permainan harga dengan skor 0,206, dan prioritas terakhir adalah memperluas mitra kerjasama (parthnership) para petani dan pengusaha penyulingan nilam dalam meningkatkan produksi.

Kata kunci: kemitraan, minyak nilam, strategi pengembangan, SWOT, AHP.

\section{PENDAHULUAN}

Minyak Nilam (Pogostemon cablin) secara internasional dikenal dengan nama Patchouli oil yang bernilai ekonomis tinggi. Minyak nilam menjadi salah satu komoditas atsiri yang mempunyai sifat fixatif (mengikat minyak atsiri lainnya) sehingga banyak dimanfaatkan dalam pembuatan farfum, detergen dan kondisioner rambut (Swamy dan Sinniah, 2016; Yang et al., 2005). Aktivitas perdangangan dunia, komoditas ini memiliki peran strategis dalam menghasilkan produk primer maupun sekunder, sehingga mampu memenuhi kebutuhan domestik maupun kebutuhan ekspor (Panjaitan, 
2014). Berdasarkan data statistik, tujuan ekspor minyak nilam Indonesia adalah Singapura, India, AS, Inggris, Jerman, Belanda dan Spanyol (Sufriadi dan Mustanir, 2015), sisanya sebagai kebutuhan pasar domestik.

Komoditas nilam menjadi salah satu tanaman perkebunan yang diusahakan di lahan kering khususnya di Kabupaten Konawe Selatan. Data produksi BPS Kabupaten Konawe Selatan 2017 merilis bahwa jumlah produksi minyak nilam dari beberapa tahun terakhir mengalami peningkatan misalnya produksi tahun 2015 mencapai $3.800 \mathrm{~kg}$ meningkat di tahun 2016 mencapai $4.630 \mathrm{~kg}$. Kabupaten Konawe Selatan menjadi daerah yang sangat potensial untuk dikembangkan budidaya tanaman nilam hingga pengolahan minyak nilam. Keberadaan agroindustri di suatu wilayah diharapkan dapat meningkatkan permintaan terhadap komoditas khususnya produk minyak nilam guna peningkatan perekonomian masyarakat.

Pelaksanaan aktivitas sebuah agroindustri tentu akan banyak membutuhkan mitra dalam operasionalnya. Maka dibutuhkan kerjasama (parthnership) dalam mengembangkan sebuah agroindustri khususnya minyak nilam. Keberadaan usaha penyulingan minyak nilam di Kecematan Baito Kabupaten Konawe Selatan digerakkan oleh salah satu lembaga ekonomi masyarakat seperti Koperasi. Lembaga ini disebut sebagai Koperasi Nilam Samaturu (KIS) yang secara khusus mengelola usaha penyulingan minyak nilam.

Kemitraan yang terjalin antara dua pihak atau lebih diharapkan dapat meraih keuntungan bersama dengan prinsip saling membutuhkan dan saling membesarkan (Budi, 2009). Fokus utama yang dijalankan KIS saat ini meliputi aspek permodalan, proses produksi dan aspek pemasaran. Berdasarkan aspek tersebut, pihak KIS perlu memperluas akses informasi dan kemitraan dalam pengembangan agroindustri minyak nilam agar berdaya saing dan berkelanjutan. Melalui sistem kemitraan dapat mengatasi masalah minimnya informasi pasar dan risiko (Daryanto, 2006), dapat menjadi solusi untuk mengatasi risiko harga produk (Fariyanti, 2008), dapat meningkatkan pendapatan petani (Indrayani 2008; Rachmawati, 2008).

Pengembangan kemitraan agroindustri merupakan kewajiban para pelaku bisnis untuk memperluas akses kerjasama baik dalam skala produksi, maupun perluasan pemasaran (Royer, 2017). Untuk meningkatkan efektifitas strategi dalam upaya peningkatan produksi, kualitas, dan stabilitas harga, diperlukan pemahaman yang mendalam terhadap faktor internal dan eksternal KIS tersebut. Salah satu teknik yang dilakukan dalam pengembangan kemitraan agroindustri nilam di Kabupaten Konawe Selatan adalah penerapan metode analisis SWOT. Menurut Rangkuti (2013) metode SWOT merupakan salah satu alat analisis untuk menyusun strategi berdasarkan kondisi internal dan eksternal yang ada pada sebuah perusahaan/industri. Output analisis tersebut dilanjutkan dengan analisa AHP. Pendekatan SWOT-AHP, intensitas kekuatan, kelemahan, peluang, dan ancaman dapat dikuantitatifkan, dan karena itu dapat dihasilkan keputusan yang realistis dan efektif dibanding dengan SWOT saja atau AHP saja (Ho, 2008). Metode AHP digunakan untuk menyederhanakan persoalan yang komplek menjadi lebih terstruktur dan mudah untuk dipecahkan, serta untuk menyederhanakan alternatif strategi berdasarkan skala prioritas (bobot) yang dihasilkan dari analisis AHP (Szulecka, 2017). Keunggulan teknik AHP dapat menguraikan masalah multi faktor atau multi kriteria yang kompleks menjadi suatu hirarki (Irawan et al., 2017). Dalam penelitian ini pendekatan SWOT-AHP diajukan untuk pengembangan kemitraan agroindustri nilam yang ada di Kabupaten Konawe Selatan. Adapun tujuan penelitian ini untuk mendapatkan strategi agroindustri dari sisi kemitraan baik dalam aspek produksi maupun aspek pemasaran.. Menganalisis kondisi eksisting baik internal maupun eksternal dalam SWOT. Penentuan strategi terpilih menggunakan analisa AHP dalam pengembangan kemitraan agroindustri nilam.

\section{METODE PENELITIAN}

Pelaksanaan penelitian ini bertempat di salah satu usaha penyulingan minyak nilam yang dikelola oleh lembaga KIS di Kecamatan Baito Kabupaten Konawe Selatan. Penelitian ini menggunakan metode perpaduan antara SWOT dengan metode AHP. Menurut Eisenhardt dan Graebner (2007) beranggapan bahwa esensi penelitian studi kasus adalah penyelidikan teori dalam konteks baru untuk memberikan wawasan dan memperkaya teori dengan kasus yang baru. Adapun tahapan penelitian ini diawali dengan melakukan studi lapangan dengan menggunakan panduan wawancara, untuk mengidentifikasi kondisi eksisting yang terdapat pada agroindustri hulu (penyulingan) komoditas nilam. Pengambilan data diperoleh dari pengurus lembaga KIS dan dua orang petani mitra dan dua orang petani non mitra.

Penentuan strategi didasarkan pada kompetensi dan pengalaman responden pakar terkait dengan penelitian dan keahliam dibidang masingmasing. Responden pakar pada penelitian AHP merupakan orang-orang yang memiliki pengetahuan, menguasai, mempengaruhi pengambilan kebijakan atau mengetahui informasi yang diperlukan. Responden pakar penlitian ini berjumlah 6 orang, diantaranya ketua KIS, distributor, dinas Koperasi dan UKM Konawe Selatan, Dinas Perindustrian dan Perdagangan Konawe Selatan, Distributor CV Silica Agung dan Perwakilan Institut Atsiri Universitas Brawijaya Malang. selanjutnya, dilakukan pemetaan terkait kekuatan, kelemahan, peluang dan ancaman 
KIS. Tahapan selanjutnya menetapkan posisi strategis dalam kuadran kartesius, untuk memastikan apakah berada pada kuadran I, II, III atau IV dan seterusnya. Posisi strategi menentukan alternatif strategi yang diambil oleh pihak Koperasi. Empat strategi utama yang dirumuskan yaitu, strategi SO (strength dan opportunities), strategi WO (weakness dan opportunities), strategi ST (strength dan treats) dan strategi WT (weakness dan treats).

Tahap selanjutnya adalah menentukan prioritas strategi yang akan dijalankan perusahaan dengan menggunakan AHP. Menurut Qashim (2015) dalam menentukan prioritas harus diketahui hirarki keputusan, setelah itu menyusun matriks perbandingan berpasangan (pairwise comparison). Matriks perbandingan berpasangan menggunakan skala 1 sampai dengan 9. Dari matriks perbandingan berpasangan, langkah selanjutnya yaitu membuat matriks prioritas dari masing - masing alternatif strategi. Dilanjutkan dengan pencarian nilai dari bobot kriteria. Langkah berikut uji konsistensi dengan mencari CI (Consistency Index) dan dilanjutkan dengan mencari CR (Consistency Rasio). Hasil perumusan strategi dapat di lihat pada Tabel 1 dan Gambar 2 untuk prioritas dalam proses pengembangan agroindustri nilam.

\section{HASIL DAN PEMBAHASAN}

\section{Pola Kemitraan KIS}

Kemitraan yang dibangun lembaga KIS meliputi kegiatan produksi dan proses pemasaran. Elemen tersebut terdiri dari para petani nilam yang tergabung dalam keanggotaan koperasi dan distributor sebagai sasaran pasar dalam memasarkan minyak nilam, kemudian dalam proses produksi pihak KIS juga bermitra dengan para pengepul kayu bakar sabagai bahan bakar utama dalam proses penyulingan minyak nilam, secara lengkap dapat dilihat pada Gambar 1. Komponen yang menjadi dasar terbentuknya kemitraan adanya kesepakatan bersama seperti penetapan harga, standar kualitas, sistem pembayaran, dan pengaturan pengiriman hasil. Mitra KIS biasanya melakukan kemitraan secara tertulis dan nontertulis sesuai dengan objek kerjasama. Sistem ini sejalan dengan penelitian Singh (2005) yang menyebutkan bahwa dalam setiap kerjasama diperlukan kontrak secara tertulis yang mencakup 4 hal yaitu harga, kualitas, kuantitas dan waktu yang harus disepakati.

Pola kemitraan yang terjalin antara pihak koperasi dengan para petani mitra saat ini adalah pola kemitraan inti plasma, dimana KIS bertindak sebagai inti plasma sedangkan petani nilam bertindak sebagai plasma. Oleh sebab itu setiap produk yang dihasilkan dari petani akan dijual kepada pihak KIS baik dalam bentuk nilam kering maupun yang sudah berbentuk minayk nilam. Hal ini berkaitan dengan teori yang diungkapkan (Sumardjo et al., 2004) bahwa inti plasma berperan menyediakan sarana produksi, menampung serta memasarkan hasil produksi yang dihasilkan plasma. KIS dengan distributor (konsumen) memiliki hubungan kemitraan dengan pola dagang umum, dimana setiap produk yang dihasilkan akan dibeli oleh pihak distributor dengan kesepakatan yang telah ditentukan bersama-sama. Kemitraan ini merupakan bagian dari kerjasama pemasaran (Khalifi, 2018).

\section{Analisis SWOT}

Metode SWOT memungkinkan sebuah organisasi/perusahaan untuk memvisualisasikan kekuatan, kelemahan, peluang dan ancaman yang dapat digunakan untuk membandingkan perusahaannya dengan pesaing (Cassidy et al., 2013). Berdasarkan hasil informasi dan kuesioner para pakar di lapangan melalui Focus Group Discussion (FGD), bersama pengurus KIS, petani nilam serta pihak terkait lainnya. Didapatkan bahwa ada tujuh faktor internal dan enam faktor eksternal yang berhasil diidentifikasi seperti pada Tabel 1 dan Tabel 2

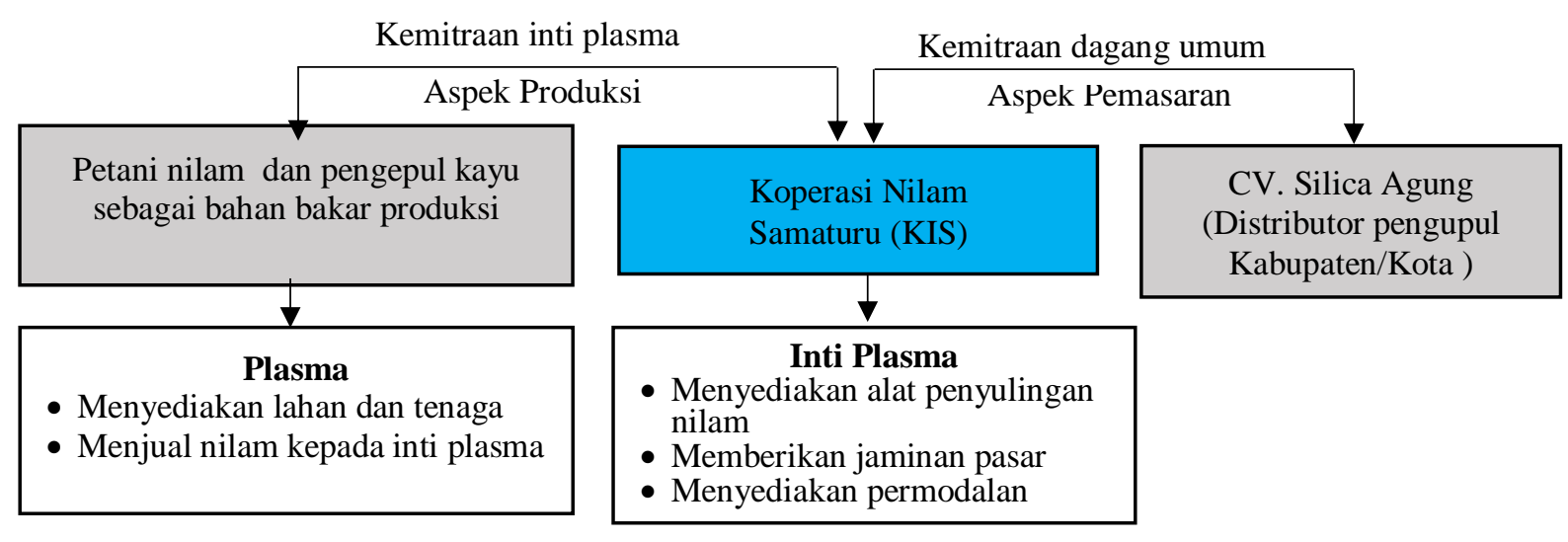

Ket :

: Lembaga penggerak/wadah dalam usaha agroindustri nilam

: Mitra dalam menjalankan usaha minyak nilam

: Peran dan fungsi dalam kemitraan

Gambar 1. Pola Kemitraan KIS 
Tabel 1. Faktor Internal

\begin{tabular}{|c|c|c|c|c|c|}
\hline \multirow{6}{*}{ 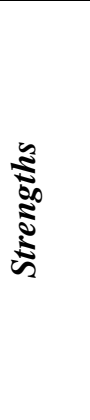 } & & IFE & $\begin{array}{c}\text { Rata- } \\
\text { rata } \\
\text { Bobot }\end{array}$ & $\begin{array}{c}\text { Rata- } \\
\text { rata } \\
\text { Rating }\end{array}$ & Total \\
\hline & & Indikator Kekuatan & & & \\
\hline & $\mathrm{S} 1$ & Pelanggan sudah tersegmentasi & 0,096 & 3 & 0,288 \\
\hline & $\mathrm{S} 2$ & $\begin{array}{l}\text { Populasi petani dalam menanam tanaman nilam masih } \\
\text { cukup tinggi }\end{array}$ & 0,124 & 4 & 0,496 \\
\hline & $\mathrm{S} 3$ & $\begin{array}{l}\text { Luasan lahan untuk budidaya komoditas nilam masih } \\
\text { memadai }\end{array}$ & 0,157 & 3 & 0,471 \\
\hline & S4 & Minyak yang dihasilkan memiliki mutu yang baik & 0,132 & 4 & $0,528 *$ \\
\hline \multirow{6}{*}{$\sum^{\frac{D}{7}}$} & & Jumlah (S) & & & 1,783 \\
\hline & W1 & Permodalan yang terbatas dalam pengembangan usaha & 0,167 & 2 & 0,334 \\
\hline & $\mathrm{W} 2$ & Kurangnya pengetahuan dan wawasan SDM & 0,157 & 2 & 0,314 \\
\hline & W3 & Masih terbatasnya alat produksi & 0,167 & 3 & $0,501 *$ \\
\hline & & Jumlah (W) & $\mathbf{1 , 0 0}$ & & 1,149 \\
\hline & & Total $(S+W)$ & & & 2,932 \\
\hline
\end{tabular}

Tabel 2. Faktor Eksternal

\begin{tabular}{|c|c|c|c|c|c|}
\hline \multirow{5}{*}{ 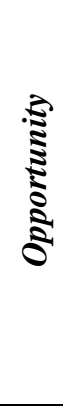 } & & $\begin{array}{c}\text { EFE } \\
\text { Indikator Peluang } \\
\end{array}$ & $\begin{array}{l}\text { Rata- } \\
\text { rata } \\
\text { Bobot }\end{array}$ & $\begin{array}{l}\text { Rata- } \\
\text { rata } \\
\text { Rating }\end{array}$ & Total \\
\hline & O1 & $\begin{array}{l}\text { Daya tahan dan kualitas produk minyak atsiri ada pada } \\
\text { nilam }\end{array}$ & 0.101 & 2 & 0,202 \\
\hline & $\mathrm{O} 2$ & Permintaan pasar dalam Negeri dan luar negeri meningkat & 0,127 & 3 & 0,381 \\
\hline & $\mathrm{O} 3$ & Kemitraan petani sebagai modal peningkatan produksi & 0,164 & 4 & $0,656^{*}$ \\
\hline & $\mathrm{O} 4$ & $\begin{array}{c}\text { Ketersediaan bahan baku dari para petani meningkat } \\
\text { Jumlah }(\mathbf{O})\end{array}$ & 0,139 & 3 & $\begin{array}{l}0.417 \\
\mathbf{1 , 6 5 6}\end{array}$ \\
\hline \multirow{5}{*}{ 䄳 } & $\mathrm{T} 1$ & $\begin{array}{l}\text { Fenomena terjadinya naik turun harga komoditi minyak } \\
\text { nilam }\end{array}$ & 0,190 & 2 & $0,380 *$ \\
\hline & $\mathrm{T} 2$ & Munculnya Kompetitor baru & 0,127 & 2 & 0,254 \\
\hline & $\mathrm{T} 3$ & Perubahan Iklim yang tidak menentu & 0,152 & 2 & 0,304 \\
\hline & & Jumlah (T) & $\mathbf{1 , 0 0}$ & & $\mathbf{0 , 9 3 8}$ \\
\hline & & Total $(\mathbf{O}+\mathbf{T})$ & & & 2,594 \\
\hline
\end{tabular}

Hasil yang didapatkan dari total nilai pada matriks IFE adalah 2,932, sedangkan total nilai EFE sebesar 2,594. Hasil skor dari internal dan eksternal menunjukan bahwa usaha penyulingan nilam yang sedang dijalankan tergolong sedang atau rata-rata. Secara lengkap matriks IE dan posisi bisnis KIS dapat dilihat dalam Gambar 3.

Berdasarkan Gambar 2, posisi bisnis minyak nilam saat ini berada pada blok di kuadran V, posisi diatas dapat dijelaskan bahwa bisnis yang sedang dijalankan KIS adalah strategi pertumbuhan/stabilitas (Growth/Stability), sehingga perusahaan atau KIS dinyatakan dalam kondisi stabil dan mampu mengembangkan bisnisnya. Adapun strategi yang umum diterapkan pada kategori ini adalah penetrasi pasar dan pengembangan produk (Robinson, 2008). Strategi yang dilakukan pada kuadran ini adalah meningkatkatkan market share dengan cara menambah segmen baru. Strategi ini dapat dilakukan dengan meningkatkan promosi baik secara online maupun offline.
Strategi ini berkaitan modifikasi terhadap produk yang ada atau penciptaan produk baru yang masih berkaitan dengan ruang pemasaran saat ini (Robinson, 2008). Menurut Pratama (2017) pengembangan produk minyak atsiri dapat dilakukan perusahaan yang bergerak di bidang pengolahan minyak atsiri menjadi berbagai produk turunan seperti parfum, aromaterapi, dan produk perawatan wajah atau kulit. Sebagai agroindustri hulu, pelaksanaan strategi pengembangan produk hanya dapat dilakukan dengan menjaga penanganan pasca panen, proses penyulingan, sehingga dapat menghasilkan minyak nilam dengan mutu yang baik. Strategi ini dapat dilihat pada ST1 dan ST2 pada perumusan strategi. Beberapa bentuk strategi ini merupakan upaya pengembangan produk yang paling memungkinkan untuk dilakukan dengan kondisi KIS saat ini. Strategi yang dapat dilakukan dapat dilihat pada WO1 yaitu dengan membuka ruang komunikasi pihak pemerintah dan lembaga dalam proses standarisasi, baik dari pengolahan maupun produk yang dihasilkan. 
Berdasarkan analisis SWOT Gambar 3 dan posisi pengembangan kemitraan agrindustri nilam di Kabupaten Konawe Selatan, maka dapat dirumuskan strategi pengembanganya sebagai berikut :

a.Mempertahankan mutu produksi minyak nilam yang dihasilkan dari petani mitra baik dari sisi input, proses dan output serta meningkatkan akses pasar yang lebih luas dengan menjalin kemitraan. Menjaga kualitas mutu menjadi faktor penting dalam melakukan ekspansi pasar yang lebih luas. Strategi pemasaran khususnya produk minyak nilam sangat penting dilakukan pengklasifikasian, Menurut Kotler (2002) terdapat dua klasifikasi jenis produk menurut tujuan pemakainnya yaitu barang konsumsi atau barang industri. Oleh karena itu, produk penyulingan nilam merupakan barang industri yang digunakan sebagai bahan baku utama untuk industri parfum, kosmetik, sabun dan obatobatan. Mempertahankan mutu menjadi alternatif startegi untuk mendapatkan dan memperluas jangkauan pasar yang luas khususnya minyak nilam.

\section{Total Faktor Strategi Internal = 2,932}

Posisi KIS

- Penetrasi pasar

- Pengembangan produk

Total Faktor

Strategi

Eksternal $=2,594$

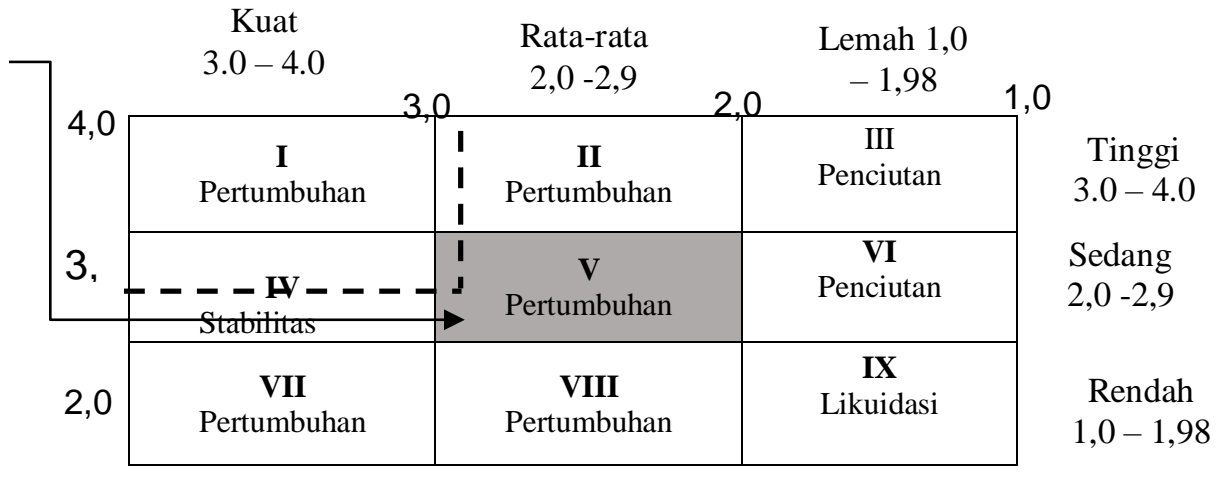

1,0 Gambar 2. Matriks Internal dan Eksternal KIS

Tabel 3. Alternatif Strategi SWOT

\begin{tabular}{|c|c|c|}
\hline Internal & $\begin{array}{l}\text { Kekuatan (Strength) } \\
\text { 1. Pelanggan sudah tersegmentasi } \\
\text { 2. Populasi petani dalam menanam tanaman } \\
\text { nilam masih cukup tinggi } \\
\text { 3. Luasan lahan untuk budidaya komoditas } \\
\text { nilam masih memadai } \\
\text { 4. Minyak yang dihasilkan memiliki mutu } \\
\text { yang baik }\end{array}$ & $\begin{array}{l}\text { Kelemahan (Weakness) } \\
\text { 1. Permodalan yang terbatas } \\
\text { dalam pengembangan usaha } \\
\text { 2. Kurangnya pengetahuan dan } \\
\text { wawasan SDM } \\
\text { 3. Masih terbatasnya alat produksi }\end{array}$ \\
\hline Peluang (Opportunity) & Strategi $\mathrm{S}-\mathrm{O}$ & Strategi $\mathrm{W}-\mathrm{O}$ \\
\hline $\begin{array}{l}\text { 1. Daya tahan dan kualitas } \\
\text { produk minyak atsiri ada } \\
\text { pada nilam } \\
\text { 2. Permintaan pasar dalam } \\
\text { Negeri dan luar negeri } \\
\text { meningkat } \\
\text { 3. Kemitraan petani sebagai } \\
\text { modal peningkatan produksi } \\
\text { 4. Ketersediaan bahan baku } \\
\text { dari para petani meningkat }\end{array}$ & $\begin{array}{l}\text { 1. Mempertahankan mutu yang dihasilkan dari } \\
\text { petani mitra dan Meningkatkan akses pasar } \\
\text { yang lebih luas dengan menjalin kemitraan } \\
\text { (S1, O1, O2) } \\
\text { 2. Memanfaatkan luas areal penanaman dan } \\
\text { petani yang berusahatani nilam untuk } \\
\text { memenuhi permintaan nilam (S2,S3, O2) } \\
\text { 3. Mempertahankan dan Memperluas mitra } \\
\text { kerjasama para petani dan pengusaha } \\
\text { penyulingan nilam dalam meningkatkan } \\
\text { produksi }(\mathrm{S} 2, \mathrm{~S} 3, \mathrm{O} 3,04)\end{array}$ & $\begin{array}{l}\text { 1. Membuka ruang komunikasi } \\
\text { dengan pihak pemerintah dan } \\
\text { lembaga dalam proses } \\
\text { standarisasi (W3, O1, O2) } \\
\text { 2. Melakukan pelatihan } \\
\text { pengembangn SDM dengan } \\
\text { bekerjasama oleh dinas terkait } \\
\text { (W2, O3) } \\
\text { 3. Menjalin kerjasama antar } \\
\text { penyuling antar kecamatan dan } \\
\text { daerah }(\mathrm{W} 3, \mathrm{O} 2)\end{array}$ \\
\hline Ancaman (Threts) & Strategi $\mathrm{S}-\mathrm{T}$ & Strategi $\mathrm{W}-\mathrm{T}$ \\
\hline $\begin{array}{l}\text { 1. Fenomena terjadinya naik } \\
\text { turun harga komoditi } \\
\text { minyak nilam } \\
\text { 2. Munculnya Kompetitor } \\
\text { baru } \\
\text { 3. Perubahan Iklim yang tidak } \\
\text { menentu }\end{array}$ & $\begin{array}{l}\text { 1. Meningkatkan pengawasan budidaya dan } \\
\text { proses pengolahan (S4, T1, T2) } \\
\text { 2. Mengantisipasi perubahan iklim dengan } \\
\text { menerapkan Good agricultural process (S2, } \\
\text { S3, T3) }\end{array}$ & $\begin{array}{l}\text { 1. Memperkuat permodalan dan } \\
\text { memanfaatkan jaringan bisnis } \\
\text { dengan internet untuk mengatasi } \\
\text { permainan harga (W1, T1, T2) } \\
\text { 2. Melakukan kerjasama dengan } \\
\text { penyuluh untuk melakukan } \\
\text { pendampingan terhadap petani } \\
\text { mitra (W1,W2, T3) }\end{array}$ \\
\hline
\end{tabular}


b. Memanfaatkan luas areal penanaman dan petani yang berusahatani nilam untuk memenuhi permintaan nilam. Minyak nilam sebagai barang industri tentu akan dibutuhkan secara terus menerus dan berkesinambungan, sehingga permintaan akan produk tersebut akan terus meningkat. Jumlah lahan dan petani nilam yang terus mengalami peningkatan harus menjadi kekuatan utama untuk dimanfaatkan oleh KIS agar mampu mengembangkan bisnis minyak nilam yang sedang dijalankan, sehingga peningkatan penjualan minyak kepada konsumen bisa ditingkatkan.

c. Mempertahankan dan memperluas mitra kerjasama (parthnership) para petani dan pengusaha penyulingan nilam dalam meningkatkan produksi. Mitra yang sudah terbangun antara pihak KIS dengan petani, maka perlu dipertahankan keberlanjutannya. Selain itu, untuk meningkatkan produksi khususnya minyak nilam diusahakan pihak KIS memperluas kerjasama kepada petani yang ada dengan pemilik ketel/penyulingan nilam baik secara formal maupun nonformal. Kemitraan yang akan dibangun harus didasarkan pada asas keterbukaan, dana saling membutuhkan, agar kerjasama tersebut bisa memberikan implikasi ekonomi bagi pelaku yang bermitra.

d. Membuka kerjasama komunikasi dengan pihak pemerintah dan lembaga dalam proses standarisasi. Agroindustri penyulingan nilam merupakan salah satu produk sentral yang dbutuhkan bagi industri parfum, sabun, dan obat-obatan. Produk minyak atsiri khususnya minyak memiliki keunggulan dibanding produk lain (Yang et al., 2005). Oleh karena itu untuk meningkatkan daya saing, maka pihak KIS perlu menjalin komunikasi bagi pemerintah dan lembaga untuk memperkuat kualitas mutu agar target pasar khususnya perusahaan/industri yang menggunakan produk tersebut dapat dijangkau.

e. Melakukan pelatihan pengembangan SDM dengan bekerjasama oleh dinas terkait. Proses pengembangan kapasitas merupakan aktivitas kunci yang harus dilakukan dalam hal peningkatan kualitas SDM dalam sebuah agroindustri. Strategi yang diharapkan adalah adanya pembinaan para petani mitra maupun non mitra. Kegiatan yang bisa dilakukan dengan meminta bantuan dari dinas terkait seperti Dinas Koperasi dan UMKM dan Dinas pertanian untuk mengadakan pelatihan secara berkelanjutan, pendampingan dalam mengembangkan lembaga KIS dan budidaya tanaman agar memiliki daya saing dimasa yang akan datang.

f. Menjalin kerjasama antar penyuling antar kecamatan dan daerah. Mengingat alat penyulingan yang dimiliki KIS masih terbatas, maka alternatif strategi yang ditawarkan adalah menjalin kerjasama dengan pemilik ketel penyulingan nilam baik dalam satu wilayah Kecamatan maupun di luar wilayah Kecamatan. Maka dengan strategi ini bisa menambah produksi secara efektif tanpa harus menunggu antrian bahan baku pada proses penyulingan minyak nilam berlangsung, karena saat ini hanya tersedia 2 unit alat yang dimiliki pihak koperasi. Meningkatkan pengawasan budidaya dan proses pengolahan merupakan alternatif strategi kegiatan evaluasi yang dilakukan KIS kepada karyawan dan petani mitra. Aktivitas ini dilakukan untuk terus memantau aktivitas kunci, baik yang berhubungan penanaman, penanganan bahan baku maupun proses penyulingan daun nilam menjadi minyak nilam yang berkualitas.

g. Mengantisipasi perubahan iklim dengan menerapkan Good agricultural process. Proses budidaya tanaman nilam merupakan bagian aktivitas kunci yang dilakukan oleh pihak koperasi. Oleh sebab itu penerapan Good agricultural process merupakan metode cara melakasanakan budidaya tanaman pertanian secara benar dan tepat sehingga diperoleh produktivitas tinggi, dan memiliki mutu yang baik. Alternatif strategi ini dibutuhkan pendampingan kepada para petani untuk bisa menerapkan proses budidaya yang baik dan penanganan pasca panen khususnya penanaman nilam hingga proses penyulingan.

h. Memperkuat permodalan dengan memanfaatkan jaringan bisnis dan internet untuk mengatasi permainan harga. Permodalan dapat dilakukan dengan memanfaatkan dukungan pemerintah dan mencari tambahan permodalan dengan bermitra dengan lembaga penyedia modal, sehingga kedepan dapat meningkatkan penjualan, menambah koneksi dan relasi serta menambah wawasan atau memperluas pengetahuan bisnis. Strategi pendukung dengan cara memanfaatkan internet seperti menggunakan media media sosial. Kekuatan itu dapat dimanfaatkan untuk melihat situasi harga komoditi atsiri yang fluktuatif.

i. Melakukan kerjasama dengan penyuluh untuk melakukan pendampingan terhadap petani mitra. Peran penyuluh dalam kegiatan pertanian sangat dibutuhkan mengingat pendidikan dan pengetahuan yang dimiliki para petani sangat minim. Strategi ini membuka ruang bagi KIS untuk bekerjasama dengan para penyuluh pertanian untuk memberikan pendampingan kepada pada petani dan non mitra untuk mengembangkan kapasitas dan kualitas terkait kegiatan budidaya, penanganan pasca penen sampai proses penyulingan.

\section{Analytical Hierarchy Process (AHP)}

Proses pembuatan keputusan atau pemecahan masalah, teknik AHP dapat digabungkan dengan menggunakan aplikasi atau Software yang berfungsi untuk fleksibilitas dan efisiensi (Syafirullah, 2014). Pemodelan AHP yang digunakan dalam penelitian ini, 
hirarki disusun terdiri dari 5 level yang terdiri dari level utama sebagai fokus/goal dari hirarki, level kedua faktor internal dan eksternal, level ketiga aktor yang berpengaruh, level keempat tujuan dan level yang kelima adalah alternatif strategi yang dihasilkan. Hirarki model AHP Secara lengkap disajikan dalam Gambar 4.

Penentuan Faktor yang berpengaruh dalam pengembangan Agroindustri nilam

Faktor yang terpilih dalam proses penyusunan hirarki strategi pengembangan agroindustri KIS adalah faktor internal dan eksternal yang merupakan faktor-faktor dengan nilai bobot tertinggi menurut matriks IFE, EFE dan SWOT. Selain itu juga pemilihan faktor tersebut disesuaikan dengan tujuan dan alternatif strategi pengembangan usaha. Dengan penilaian dari penggabungan pendapat para pakar didapatkan hasil prioritas seperti pada Tabel 4.

Tabel 4. Faktor yang berpengaruh dalam strategi pengembangan usaha

\begin{tabular}{lcc}
\hline $\begin{array}{l}\text { Faktor internal dan } \\
\text { ekstenal }\end{array}$ & Bobot & Prioritas \\
\hline $\begin{array}{l}\text { Minyak yang } \\
\text { dihasilkan memiliki }\end{array}$ & $\mathbf{0 , 2 1 1}$ & 1 \\
$\begin{array}{l}\text { mutu yang baik } \\
\text { Permintaan pasar masih } \\
\text { meningkat }\end{array}$ & 0,184 & 2 \\
$\begin{array}{l}\text { Permodalan yang } \\
\text { terbatas }\end{array}$ & 0,143 & 3 \\
$\begin{array}{l}\text { Jumlah alat produksi } \\
\text { terbatas }\end{array}$ & 0,133 & \\
$\begin{array}{l}\text { Luasan lahan budidaya } \\
\text { nilam masih memadai }\end{array}$ & 0,114 & 4 \\
$\begin{array}{l}\text { Kemitraan petani nilam } \\
\text { Fluktuasi harga nilam }\end{array}$ & 0,097 & 0,096 \\
$\begin{array}{l}\text { Perubahan iklim yang } \\
\text { tidak menentu }\end{array}$ & 0,022 & 6 \\
\hline
\end{tabular}

Berdasarkan hasil analisis dari penilaian para pakar, didapatkan bahwa prioritas yang perlu diperhatikan dalam penyusunan sebuah strategi adalah produk minyak nilam yang dihasilkan harus memiliki mutu yang baik, sehingga menempati prioritas teratas dengan skor 0,211, kemudian juga didukung banyaknya permintaan pasar dengan skor 0,184. Namun dari kondisi internal KIS saat ini seperti permodalan dan terbatasnya alat produksi menjadi tantangan yang harus dihadapi, karena berada pada prioritas ketiga dan keempat.

Penentuan Aktor Yang Berpengaruh Dalam Pengembangan Agroindustri Nilam

Keberhasilan sebuah bisnis tidak terlepas dari peran aktor, karena peran aktor dinilai sebagai kunci sukses menjalankan sebuah strategi bisinis khususnya pengambangan agroindustri nilam. Beberapa aktor kunci yang dianggap memberikan pengaruh positif terhadap berkembangnya sebuah bisnis dapat dilihat pada Tabel 5 .

Tabel 5. Aktor prioritas dalam pengembangan agroindustri nilam

\begin{tabular}{lcc}
\hline \multicolumn{1}{c}{ Aktor } & Bobot & Prioritas \\
\hline Pimpinan koperasi & 0,450 & 1 \\
Lembaga & 0,289 & 2 \\
pemasaran & & \\
Pemerintah & 0,261 & 3 \\
\hline
\end{tabular}

Berdasarkan prioritas pada Tabel 5 menunjukkan bahwa pengaruh yang sangat relevan terhadap pengembangan usaha khususnya nilam adalah pimpinan koperasi dengan skor sebesar 0,450, karena penggerak bisnis penyulingan nilam dikelola secara langsung oleh pengurus KIS, kemudian diikuti lembaga pemasaran dan pemerintah dengan skor 0,289 dan 0,261 .

\section{Penentuan Tujuan Dalam Strategi Pengembangan Agroindustri Nilam}

Penetapan tujuan merupakan hal yang harus dilakukan untuk mendapatkan prioritas alternatif strategi. Menurut Christensen dan Leu (2015) dalam penelitiannya bahwa tujuan pengembangan sebuah bisnis minimal ada tiga unsur yang memberikan pengaruh terhadap pengembangan kemitraan. Hasil penilaian dari pendapat para pakar dari beberapa tujuan didapatkan hasil prioritas seperti pada Tabel 6.

Tabel 6. Tujuan prioritas dalam pengembangan agroindustri nilam

\begin{tabular}{lcc}
\hline \multicolumn{1}{c}{ Tujuan } & Bobot & Prioritas \\
\hline Peningkatan & 0,386 & 1 \\
$\begin{array}{lcc}\text { Pendapatan } \\
\text { Perluasan Kemitraan }\end{array}$ & 0,338 & 2 \\
$\begin{array}{l}\text { Pembinaan dan } \\
\text { Pengembangan }\end{array}$ & 0,312 & 3 \\
\hline
\end{tabular}

Berdasarkan analisis AHP dari pendapat para pakar, ditemukan bahwa tujuan prioritas yang diinginkan sebuah perusahaan seperti KIS adalah peningkatan pendapatan dengan total skor 0,386. Prioritas kedua dan terakhir adalah perluasan kemitraan dan pembinaan pengembangan.

\section{Penentuan Alternatif Strategi Pengembangan Agroindustri Nilam}

Proses penentuan alternatif strategi, ditentukan berdasarkan pada total nilai skor tertinggi yang diperoleh dari masing-masing faktor internal dan eksternal KIS dan hasil analisa dari penyusunan SWOT. Langkah berikut dihibungkan dengan tiga tujuan pengembangan bisnis sebelumnya yang disesuaikan dan dapat mewakili masing-masing strategi seperti SO, ST, WO dan WT. Berdasarkan hasil analisis dengan teknik AHP dan didasarkan pada penggabungan pendapat para pakar, berdasarkan prinsip perbandingan berpasangan (pairwise 
comparisons) didapatkan hasil prioritas alternatif strategi pengembangan usaha seperti pada Tabel 7 .

Tabel 7. Alternatif strategi dalam pengembangan agroindustri nilam

\begin{tabular}{llc}
\hline \multicolumn{1}{c}{ Alternatif Strategi } & Bobot & Prioritas \\
\hline $\begin{array}{l}\text { Meningkatkan akses } \\
\text { pasar yang lebih luas } \\
\text { dengan menjalin }\end{array}$ & 0,369 & \\
kemitraan & \\
\hline $\begin{array}{l}\text { Melakukan pelatihan } \\
\text { pengembangn SDM } \\
\text { dengan bekerjasama } \\
\text { oleh dinas terkait }\end{array}$ & 0,250 & 2 \\
\hline $\begin{array}{l}\text { Memperluas mitra } \\
\text { kerjasama } \\
\text { (parthnership) para } \\
\text { petani dan pengusaha } \\
\text { penyulingan nilam } \\
\text { dalam meningkatkan } \\
\text { produksi }\end{array}$ & 0,247 & \\
$\begin{array}{l}\text { Memperkuat } \\
\text { permodalan dengan } \\
\text { memanfaatkan jaringan } \\
\text { bisnis dan internet } \\
\text { untuk mengatasi } \\
\text { permainan harga }\end{array}$ & 0,206 \\
\hline
\end{tabular}

Berdasarkan penentuan alternatif strategi yang ada, didapatkan bahwa prioritas utama adalah meningkatkan akses pasar yang lebih luas dengan skor
0,369. Ini mengindikasikan perluasan akses pasar menjadi sangat strategis baik saat ini maupun untuk masa mendatang (Yusuf, 2012). Alternatif yang ditawarkan adalah dengan memperluas akses pasar dengan menjalin kemitraan. Alternatif kedua melakukan pelatihan pengambangan SDM dengan bekerjasama dengan dinas terkait dengan nilai bobot 0,250, hal ini didasarkan pada analisa SWOT sebelumnya dalam analisa kelemahan KIS terdapat faktor kelemahan internal berupa rendah pengetahuan dan wawasan sumber daya manusia (SDM) baik dalam proses budidaya maupun proses penyulingan nilam. Oleh sebab itu perlu dilakukan kerjasama dengan dinas terkait seperti Dinas Koperasi dan UKM (Gambar 3).

\section{Implikasi Manajerial}

Agroindustri secara umum tidak akan bergerak dan tumbuh tanpa adanya para konsumen produk yang dihasilkan dan adanya para pemasok bahan baku yang dibutuhkannya. Untuk itu peran konsumen dan pemasok bahan baku dalam agroindustri nilam juga membutuhkan dukungan berbagai aktor atau kelembagaan lainnya, termasuk dukungan pemerintah dan lembaga permodalan dan sebagainya (Miayata $e t$ al., 2009). Hal ini relevan dengan hasil analisis SWOT dan AHP yang telah dilakukan. Dalam upaya pengembangan kemitraan agroindustri nilam di wilayah Kabupaten Konawe selatan, maka dapat diusulkan seperti pada Gambar 4.

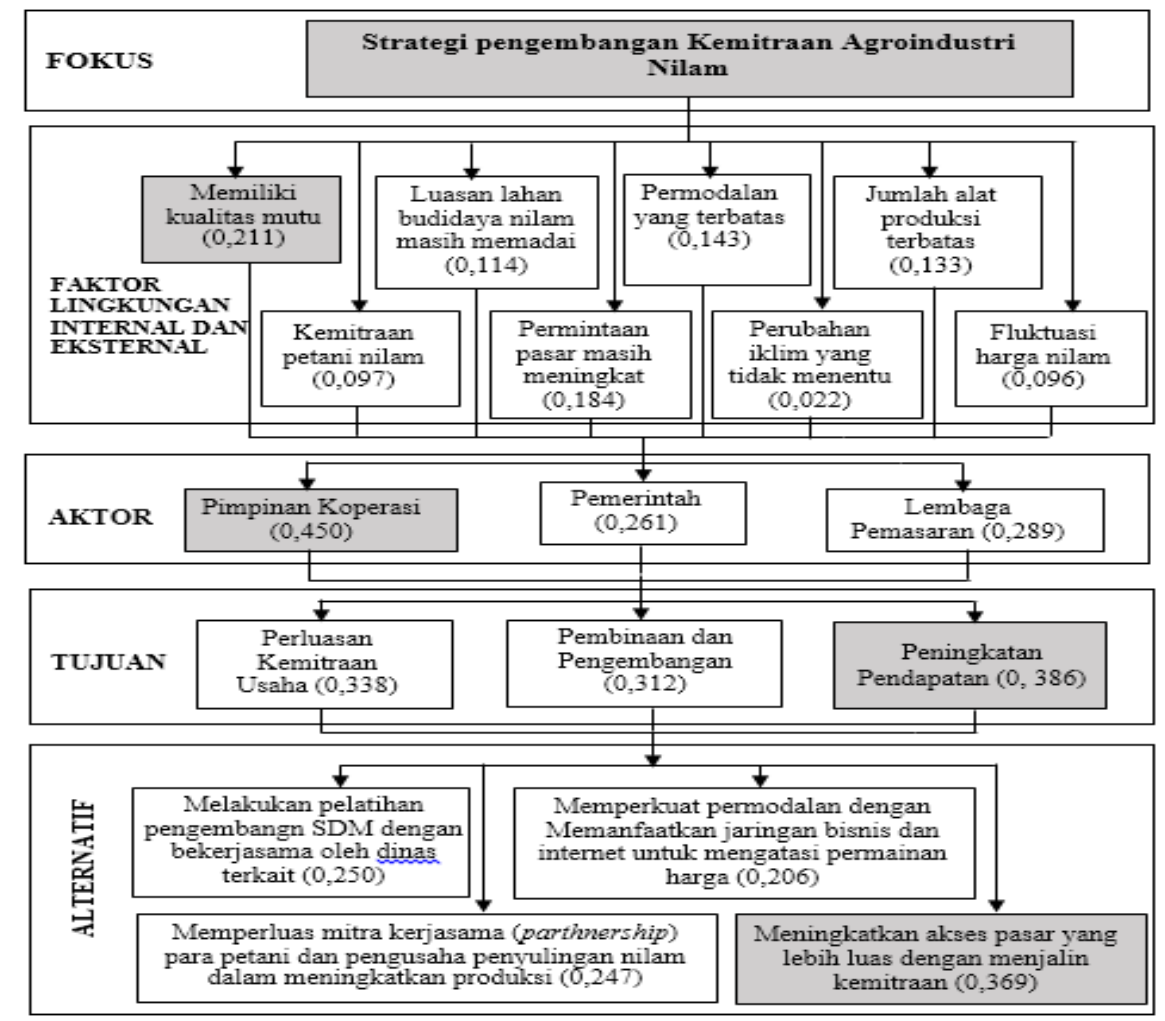

Gambar 3 Alternatif strategi berdasarkan AHP 


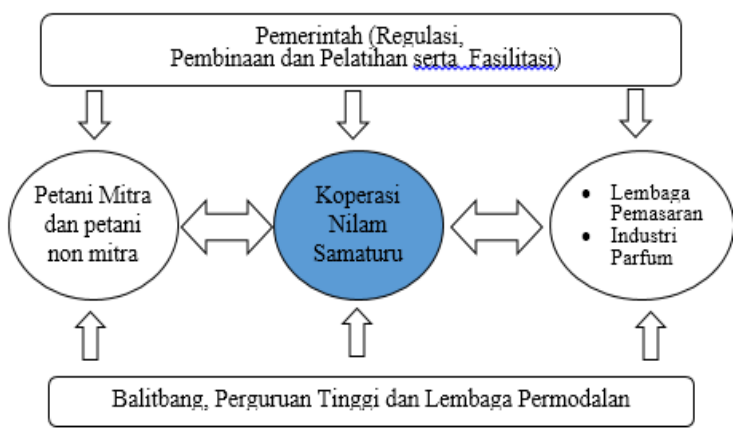

Gambar 5. Model Usulan Pengembangan Kemitraan agroindutri Nilam

Posisi KIS sebagai wadah/aktor penggerak usaha penyulingan nilam, maka diharapkan peran pemerintah dapat secara optimal dan meningkatkan efektifitas agar keseimbangan dalam kemitraan yang dibangun antara petani dengan KIS, KIS dengan lembaga pemasaran, dapat terpelihara dengan baik dan mutualistik. Upaya pemerintah tercermin dengan regulasi dengan kebijakannya yang diterbitkannya. Lembaga dibawah pemerintah yang dapat berperan, diantaranya Dinas Pertanian, Dinas Koperasi dan UKM serta Dinas Perindustrian dan Perdagangan. Kemudian juga peran badan penelitan dan pengembangan perlu lebih responsif terhadap dinamika interaksi antara petani dan pelaku agroindustri agar dapat mengembangkan teknologi yang relevan dengan realita kebutuhan kedua belah pihak dalam bermitra (Lakitan, 2012). Hal ini serupa dengan peran lembaga permodalan dalam mendukung pengembangan usaha kecil dan menangah dalam bentuk usaha penyulingan nilam.

\section{KESIMPULAN DAN SARAN}

\section{Kesimpulan}

Berdasarkan hasil analisis yang dilakukan, maka dapat disimpulkan bahwa hasil identifikasi sistem kemitraan yang dibangun lembaga KIS adalah pola inti plasma untuk aspek produksi dan pola dagang umum untuk aspek pemasaran. Hasil dari pembobotan SWOT dan AHP diperoleh bahwa posisi KIS dalam melakukakan usaha penyulingan berada di posisi pertumbuhan yang artinya alternatif strategi pertama perusahaan seperti koperasi harus melakukan penetrasi pasar dengan memperluas kemitraan di kalangan petani sebagai pemasok bahan baku serta menambah mitra distributor dalam memasarkan minyak nilam. Alternatif kedua, melakukan pelatihan pengembangn SDM dengan bekerjasama oleh dinas terkait dalam lembaga pemerintah. Alternatif ketiga, memperkuat permodalan dengan memanfaatkan jaringan bisnis dan internet untuk mengatasi permainan harga, dan alternatif terakhir memperluas mitra kerjasama (parthnership) para petani dan pengusaha penyulingan nilam dalam meningkatkan produksi dari sebelumnya.

\section{Saran}

Berdasarkan rekomendasi hasil yang didapatkan, maka dapat diberikan saran untuk pengembangan usaha agroindustri nilam khususnya pada KIS sebagai berikut:

1. Memaksimalkan kemitraan dengan pihak pemerintah dan lembaga riset untuk mengembangkan baik dibidang produksi, SDM, pemasaran melalui dukungan penelitian dan pelatihan.

2. Strategi yang dihasilkan akan memberikan dampak positif jika diimplementasikan oleh pihak KIS untuk meningkatkan kinerja baik dalam skala produksi maupun pemasaran sehingga dapat bersaing baik dalam tingkat lokal, nasional hingga internasional

3. Untuk pengembangan ilmu pengetahuan kedepannya disarankan adanya kajian mendalam terkait pengelolaan logistik minyak nilam baik dari proses penyulingan sampai menghasilkan produk yang ramah lingkungan dan berkelanjutan, kemudian juga perlu dilakukan penelitian tentang kepuasan petani mitra maupun nonmitra terhadap kinerja lembaga koperasi dalam mengelolah usaha penyulingan minyak nilam di daerah sentra produksi

\section{DAFTAR PUSTAKA}

Badan Pusat Statistik. 2016. Provinsi Sulawesi Tenggara dalam angka 2017: BPS Prov. Sultra.

Badan Pusat Statistik. 2017. Kabupaten Konawe Selatan dalam angka 2017: BPS Kab. Konsel.

Cassidy CM, Glissmeyer MD, dan Capps CJ. 2013. Mapping an internal-external (ie) matrix using traditional and extended matrix concepts. Journal Applied Business Research. 29 (5): 1523-1528.

Christensena D dan Leu TB. 2015. A DanishVietnamese partnership for business and technology development in solid waste management. Resources Conservation and Recycling. 105 (1): 123-133.

Dewi IA dan Imam S. 2007. Application of analytical hierarchy process method to analyze factors that determine the quality of packaged fishballs. Jurnal Teknologi Pertanian. 8 (1): 19-25.

Direktorat Jenderal Perkebunan. (2016). Statistik Perkebunan Indonesia Komoditas Nilam 2015-2017. Jakarta: Kementerian Pertanian.

Fariyanti A. 2008. Perilaku ekonomi rumah tangga petani sayuran dalam menghadapi risiko produksi dan harga produk di kecamatan pangalengan kabupaten Bandung. [Disertasi]. Bogor: Institut Pertanian Bogor. 
Ho W. 2008. Integrated analytic hierarchy process and its applications - a literature review. Journal Oper Res. 186 (1): 211-228.

Irawan JP, Imam S, dan Siti AM. 2017. Model analysis and mitigation strategy of risk in tempe chips production. Jurnal Teknologi dan Manajemen Agroindustri. 6 (2): 88-96.

Lakitan B. 2012. Membangun kemitraan agroindustri,menuju ketahanan dan kedaulatan pangan. Seminar Nasional Hari Pangan Sedunia (HPS). Palangkaraya.

Miyata S, Minot N, dan Hu D. 2009. Impact of contract farming on income: lingking small farmers, packers, and supermarket in China. World development. 37 (11): 1781-1790.

Mustaniro SA, Chafida RC, dan Imam S. 2016. Marketing strategic planning of "dewata" apple beverages using quantitative strategic planning matrix method. Jurnal Teknologi dan Manajemen Agroindustri. 5 (1): 21-29.

Panjaitan S dan Nuraen Y. 2014. Teknik pengembangan nilam (pogostemon cablin benth) di Kalimantan Selatan. Balai Penelitian Kehutanan Banjarbaru. 7 (1): 31-43.

Qashim A. 2015. Penerapan metode analytic hierarchy process (AHP) untuk sistem pedukung keputusan. Jurnal Ilmiah Ilmu Komputer. 1(1):8-14.

Royer A, Jos B, dan Gumataw, KA. 2017. Cooperatives, partnerships and the challenges of quality upgrading: A case study from
Ethiopia. Journal Co-operative Organization and Management. 5 (1): 48-55.

Singh R,Tripathi RS, dan Singh S. 2005. Contract farming in potato production: an alternative for managing risk and uncertainty. Agricultural Economics Research Review. 18 (1): 47-60.

Sufriadi E dan Mustanir. 2015. Strategi pengembangan menyeluruh terhadap minyak nilam (Patchouli Oil) Di Provinsi Nanggroe Aceh Darussalam. Jurusan Kimia FMIPA. Universitas Syiah Kuala Banda Aceh.

Sumardjo, Jaka, S, dan Wahyu AD. 2004. Teori Dan Praktik Kemitraan Agribisnis. Jakarta: Penebar Swadaya.

Yang N, Emmyzar dan Wiratno, 2005. Budidaya Tanaman Nilam. Badan penelitian dan pengembangan pertanian balai penelitian tanaman obat dan aromatika.

Szulecka J dan Elizabeth MZ. 2017. Forest plantations in Paraguay: Historical developments and a critical diagnosis in a SWOT-AHP framework. Land Use Policy. 60 (1): 384-394.

Wibowo W. 2009. Analisis internal dan eksternal matrik dalam strategi pengembangan objek wana wisata grajagan. Jurnal Ekonomi Bisnis 14 (2): 161-170. 